\title{
A Snapshot of the Evolution of Pharmaceutical Regulations in China and Hong Kong
}

China's foreign exchange reserves topped the world with US\$2.13 trillion by the end of June, 2009. China has emerged as a big pharmaceutical market. Since 2001, China has introduced significant regulatory changes to strive to become compatible with international standards. These include restructuring of the State Food and Drug Administration and amending pharmaceutical regulations. The developments and updates on the pharmaceutical regulatory systems in China and Hong Kong are of great interest to pharmaceutical manufacturers and researchers. Data from recent ongoing clinical trials in Asia along with the pharmaceutical regulatory challenges and opportunities for China and Hong Kong are described. Regulatory cooperation among regional Asian countries may result in a win-win situation and a bright future for all.

\section{Key Words \\ Pharmaceutical regulatory system; Regulatory harmonization; Regulatory consultation; China; Hong Kong \\ Correspondence Address \\ Dr. Bing Bing Lin, 9F-1, \#332, Sec. 1. Tung-Hwa South Road, Taipei (106). Taiwan (email:a332199@ gmail.com).}

\section{INTRODUCTION}

According to an estimate in July 2008, China has a population of $1,330,044,544$, a total land area of $9,596,960 \mathrm{~km}^{2}$, with US $\$ 6,100$ GDP per capita (gross domestic product at purchasing power parity) (1). Hong Kong has a population of $7,018,636$, on a total area of $1,092 \mathrm{~km}^{2}$, with US\$45,300 GDP per capita. According to the People's Bank of China, China's foreign exchange reserves topped the world with US $\$ 2.13$ trillion by the end of June 2009 (2). China is one of the most promising emerging pharmaceutical markets. All of the top 10 pharmaceutical companies are trying to target the Chinese sector. The drug market in China in 2007 was US $\$ 17.6$ billion. It has been growing at a rate of $30 \%$ and is expected to continue its expansion for the coming years, becoming potentially the fifth largest drug market in the world by 2011 (3). Since 2001, China has introduced significant regulatory changes to strive to become compatible with international standards. These include reorganizing the former State Drug Administration into the State Food and Drug Administration (SFDA). The developments and updates on the pharmaceutical regulatory systems in China and Hong Kong are of great interest to researchers, regulators and policy makers in pharmaceutical industry. However, it seems limited related research is being reported. Therefore, a snapshot of the evolution of pharmaceu- tical regulatory systems in China and Hong Kong is described in this article.

\section{EVOLUTION OF PHARMACEUTICAL REGULATORY SYSTEMS IN CHINA}

On December 1, 2001, the "Drug Administration Law of the People's Republic of China" was promulgated. China earnestly fulfilled its commitments to the World Trade Organization (WTO) and implemented a 6-year data protection system for new chemical entities (NCEs). In 2003, the SFDA was established, governed by the State Department. SFDA, as the overall regulator of pharmaceuticals and medical devices (as well as food, health foods, and cosmetics), is in charge of the formulation of laws and administrative rules regarding pharmaceuticals and the supervision of their enforcement, including amending drug registration, establishing a monitoring system for adverse events, reevaluating pharmaceuticals to be withdrawn, enhancing intellectual property protection, and changing drug import licensing (4).

\section{THE RESTRUCTURING OF SFDA}

In June 2005, a corruption scandal had a severe impact on the pharmaceutical regulatory system in China. It was found that SFDA officials had accepted bribes from pharmaceutical companies to approve untested medicines and issue production licenses and certificates. Shao Mingli replaced Zheng Xiaoyu as president of SFDA 
in Beijing to fix the problem. Shao was transferred from Shandong Province, where he had served since 1995. Before he replaced Zheng, he was the deputy director of SFDA and in charge of good manufacturing practice certification. In 2007, Zheng was executed and the Chinese government announced a 5-year plan to enlarge and improve its drug quality inspection forces to supervise drugs and medical devices. Since then, drug safety has been regarded as the highest priority by China's SFDA.

In March 2008, SFDA was restructured under the supervision of the Department of Health. Besides the executive departments and general office (Department of Finance Planning), SFDA now has seven main departments, including Policy and Regulations, Food Safety Supervision, Food Safety Coordination, Drug Registration, Drug Safety and Inspection, Drug Market Compliance, and Medical Devices (4). There are other evaluation centers of SFDA subsidiaries such as the Center for Drug Evaluation (CDE). wherein there are 11 groups with 113 staff members, and the National Institute for the Control of Pharmaceutical and Biological Products (NICPBP).

\section{THE MEASURE FOR DRUG REGISTRATION REGULATION IN CHINA}

On October 1, 2007, "The Measure for Drug Registration Regulation" (which contains 15 chapters, 177 articles, and 6 appendixes) was put into effect to strengthen China's drug approval system and to encourage innovation. These measures provide the detailed requirements and procedures of application and approval for drug registration for traditional Chinese medicine and natural medicines, chemical drugs and biological drugs, and the timeline for clinical trials. Chemical drug registration categories and related minimum numbers of clinical trial subjects for drug registration in China are also stated, as follows.

There are six categories for chemical drug registration in China:

Category I: New drug not yet approved in any country.
Category II: A new route of administration not yet approved in any country.

Category III: Drug commercially available overseas but not yet approved in China (also called Class III import drug registration).

Category IV: Drug made by changing the acidic or alkaline radicals or metallic elements of the salt of a drug commercially available in China without changing the original pharmacological effects.

Category V: Changed dosage form of a commercially available drug in China without changing the route of administration.

Category VI: Drug with existing national standards in China (ie, generic drug).

There are minimum numbers of clinical trial subjects for testing drug products:

1. Chemical drug registration of Category I and Category II:

For phase 1 clinical trials, the minimum number of subjects is $20-30$.

For phase 2 clinical trials, the minimum number of subjects is 100 .

For phase 3 clinical trials, the minimum number of subjects is 300 (1.000 for contraceptive drugs).

For phase 4 clinical trials, the minimum number of subjects is 2,000 .

2. Chemical drug registration of Category III-IV: Pharmacokinetic (PK) study plus 100 pairs of patient subjects, which means 100 subjects allocated to the control group and another 100 subjects in the test group, a total of 200 subjects, are the least required in clinical trial (500 subjects for testing contraceptive drugs with at least 12 periods).

3. Chemical drug registration of Category V: Bioequivalent study or 100 pairs of patient subjects in clinical trial (except for injection).

\section{ACCOUNTABILITY OF DRUG RECALL IN CHINA}

On December 14, 2007, "The Provisions for Drug Recall" (SFDA Order No. 29) was issued (5). According to the Provisions, drug manufacturers, including overseas manufacturers of imported drugs, recall drugs with potential health hazards. The Provisions increase corporate re- 
sponsibility, and state that drug manufacturers should be the first to be held accountable for the safety of the drugs they sell. The Provisions specify that overseas manufacturers of imported drugs have the same legal obligations as domestic drug manufacturers for drug recalls. The issue of dug safety remains the biggest concern for China.

On June 3, 2008, the SFDA issued "The Requirements for On-site Inspection for Drug Registration" as part of the drug approval process to audit the preclinical and clinical study sites and manufacturing sites that needed to be certified to improve the quality and safety of drugs produced in China (6). This is a top-down mandatory requirement for clinical study sites and manufacturing sites that needed to be in the officially certified listing.

\section{WORKLOAD IN CHINA'S SFDA}

In 2002, 2003, and 2004, China's SFDA received $10,815,14,663$, and 21,129 applications for new drug registration, respectively (3). Although several of them were NCEs, most of the applications were for new dosage forms or new routes of administration of existing traditional Chinese medicines. In 2004, the US FDA received 148 new drug applications (NDAs). In 2008, China's SFDA received 3,414 cases for drug registration, which is a $75 \%$ decrease from 2006 and an $18 \%$ decrease from 2007, mainly due to the reduction of the application for generic drugs and new formulations because the clinical study sites and manufacturing sites needed to be certified since June 3, 2008. Also in 2008, China's SFDA approved 434 cases for clinical trials, including 52 NCEs. SFDA approved 165 applications (including five NCEs) for new drug manufacturing and approved 99 imported drug applications and 1,502 applications for generic drugs (3).

\section{SPECIAL TRACK SYSTEM FOR DRUG APPROVAL IN CHINA}

On May 20, 2009, SFDA published "Special Review and Approval Procedure for Drug Registration" (SFDA Decree No. 21) to provide a special track system for drug approval in China in the hope of encouraging the research and development of new drugs (7). The decree adopted special review and approval with respect to innovative drugs and new drugs for serious and life-threatening diseases and to address unmet medical needs. The SFDA may implement special review and approval in such cases as the following:

1. Active ingredients extracted from plants, animals. minerals, and so on, and their preparations not yet marketed in China, and newly discovered Chinese crude drugs and their preparations

2. Chemical drug substances and their preparations and biological products not yet approved for marketing in China or abroad

3. New drugs for the treatment of diseases such as AIDS, malignant tumors, rare diseases, and so on with significant clinical advantages

4. New drugs for unmet medical needs, for which effective therapeutic methods are not available (including Sichuan Province earthquake relief products), or drugs for emergency use (eg, severe acute respiratory syndrome).

SFDA will respond in accordance with the following circumstances:

1. Where the president of the People's Republic of China declares a state of emergency or the State Council decides that certain areas within a province, autonomous region, or municipality directly under the Central Government are in a state of emergency.

2. Where the contingency program for public health emergencies is initiated according to law.

3. Where the Drug Reserve Department or the Health Administrative Department of the State Council proposes a special review and approval for drugs having existing national drug standards.

4. Other circumstances applicable to special review and approval.

\section{EVALUATION PROCESS AND TIME NEEDED FOR DRUG REGISTRATION IN CHINA}

There are two tiers of submission required for new drug approval in China (4). First, the clinical trial application needs to be submitted to SFDA (evaluation time: 7-9 months). NICPBP 
and CDE are under the supervision of SFDA. The sample needs to be analyzed at the NICPBP or authorized provincial institute for drug control (normally, this takes 60 working days). Then the test would be mailed directly to the CDE. CDE spends another 120 days for technical review and data evaluation. Supplementary data may be requested with a 4 -month submission deadline. It takes 9 months total review time for an investigational new drug (IND) to receive approval to conduct clinical trials. This system is somewhat different from that adopted by the US FDA, which allows sponsors to conduct clinical trials 30 days after IND submission without notice of safety concern. In China, an IND has 9 months review time, just like an NDA or market approval application. The submission of import drug certification to SFDA is also required in the first 9 months for IND review for import drugs and yet it is not necessary for domestic drugs. The Chinese government will issue a Certificate of Pharmaceutical Product (CPP) upon the approved domestic drug manufacturer's request. The original approval document is not the standard format of CPP. The clinical trials may take 6-24 months to complete (or 6-18 months for a PK study plus phase 3,100 pairs of patient subjects in a clinical trial). Different categories of drug application in China need to meet different requirements, while the Category I chemical drug application, that is, a new drug not yet approved in any country, may encounter the strictest challenge during the review process for market approval.

After the clinical trials are completed, the NDA will be submitted to SFDA and the review time is another 9 months. Finally, CDE/SFDA officials may call upon key opinion leaders (KOL), such as university professors, to have a face-to-face meeting with the sponsor on a weekend, not a weekday, for the convenience of the KOL, to conclude the drug evaluation process. An approval or disapproval document will be officially issued by SFDA to the applicant. The total evaluation timeline to approve a drug registration in China is 28 to 40 months. For generic drugs that require no clinical trial, the review process could be completed within 10 months.

\section{PHARMACEUTICAL REGULATORY FRAMEWORK IN HONG KONG}

In Hong Kong, the Hospital Authority is the major user of pharmaceutical products, representing more than $70 \%$ of the total industry sales. Drugs must be registered. Medical devices do not require registration. The Medical Device Control Office registers Class II, III, and IV devices on a voluntary basis. Registration is scheduled to become mandatory in the future (8).

The Pharmacy and Poisons Board (PPB) was established according to "The Pharmacy and Poisons Ordinance," Article 138 of Hong Kong Law, that all pharmaceutical products need to be registered with the $\mathrm{PPB}$ before being launched on the market. Applications for registration of pharmaceutical products are assessed by the PPB on the basis of their safety, efficacy, and quality. The application needs to include documentation of safety, efficacy, and CMC (chemistry, manufacturing, and control) and a foreign postmarket surveillance report.

\section{THE REGULATORY FRAMEWORK FOR CLINICAL TESTING OF NEW DRUGS}

The 41 public hospitals in Hong Kong, which provide $90 \%$ of the medical care to 7 million populations, are organized into seven clusters. The cluster ethics committees operate according to international standards, including the Declaration of Helsinki, International Conference of Harmonization (ICH) Good Clinical Practice (GCP), and also according to a unified operational guideline. The cluster institutional review board (IRB), registered with the US Office for Human Research Protection, handles 300 protocols annually. Meetings are scheduled every 2 weeks. The Clinical Trials Centre (CTC), established under the Faculty of Medicine of the University of Hong Kong in 1998, is the first. and complies with ICH GCP guidelines and international standards. Generally, a global clinical trial means the clinical trial is initiated by a foreign sponsor, while the investigational sites are selected from different countries, mostly 
covering several continents. The test products involved in the global clinical trials may not be submitted for registration in China or Hong Kong later. There were 205 ongoing global clinical trials conducted in Hong Kong in early 2008 and a projected 150,000 subject visits for the first 365 trial protocols. The CTC has established a trial network, ClinCluster, including 41 public hospitals, contracts, budgets, ethics committee applications, and drug regulatory applications. Since the introduction of the $\mathrm{ICH}$ GCP guideline in 1996, Hong Kong has participated in over 1,000 global clinical trials, all requiring ICH GCP compliance. Hong Kong has established a sound clinical infrastructure in terms of transportation, trained work force, legal framework, and English skills. Hospital records are all in English, computerized and stored in a central computer (9).

The first requirement for a clinical trial in Hong Kong is an ethics committee approval, which is followed by a regulatory approval for clinical trials and an import license for the test drug. These regulations apply only to drug trials but not to device or cell therapy trials, which are not government regulated and require only ethics committee approval. With its relatively smaller population. Hong Kong is one of the leading clinical trial cities (10). The drug trials in Hong Kong, within accredited therapeutic areas in recognized medical institutions, can be used in filing new drug applications in China.

\section{EVALUATION PROCESS AND TIME NEEDED FOR DRUG REGISTRATION}

There are two committees responsible for drug registration in Hong Kong:

1. The Registration Committee of the PPB examines and approves applications for registration. The manufacturers or importers of the new pharmaceutical products need to submit two valid CPPs.

2. The Poisons Committee of the PPB determines the categorization of approved pharmaceutical products.

The PPB endorses the recommendation of both committees. The Registration Committee, the Poisons Committee, and the PPB meet in con- secutive months throughout the year for product registration. PPB convenes four times every year to consider registration application.

The PPB lacks in-house regulatory reviewers. The approval process for a normal clinical trial takes 2-3 months, and it takes more than 9 months to complete the overall registration for a new pharmaceutical product in Hong Kong.

\section{DATA OF LISTED CLINICAL TRIALS IN ASIA}

Based on data in the US National Institutes of Health clinical trial registry, ClinicalTrials.gov (11), accessed on July 8,2009 , the numbers of clinical studies in Asia-Pacific countries are listed in Table 1. Similar data for Canada, Germany, the United Kingdom, and the United States are provided as a reference. Australia, Taiwan, Korea, China, Japan, and India are the leading countries in terms of ongoing clinical trials. Regulatory cooperation in the Asia-Pacific re-

\begin{tabular}{|lccc|}
\hline $\begin{array}{l}\text { Data on Clinical Trials Accessed in Asia-Pacific } \\
\text { Countries, Conada, Germany, the United Kingdom, } \\
\text { and the United States }\end{array}$ & T A B L E I \\
\cline { 2 - 4 } $\begin{array}{l}\text { Total } \\
\text { Country }\end{array}$ & Trials & Industry & $\begin{array}{c}\text { University/ } \\
\text { Organization }\end{array}$ \\
\hline Australia & 652 & 469 & 249 \\
\hline Canada & 2,193 & 961 & 1,475 \\
\hline Chino & 592 & 242 & 378 \\
\hline Germany & 1,890 & 1,124 & 924 \\
\hline Hong Kong & 248 & 152 & 109 \\
\hline India & 384 & 290 & 106 \\
\hline Japan & 466 & 281 & 200 \\
\hline Korea & 616 & 398 & 268 \\
\hline Malaysia & 90 & 85 & 7 \\
\hline New Zealand & 155 & 120 & 42 \\
\hline Philippines & 100 & 97 & 8 \\
\hline Singapore & 225 & 119 & 115 \\
\hline Taiwan & 821 & 248 & 597 \\
\hline United Kingdom & 1,231 & 716 & 583 \\
\hline United States & 12,754 & 5,146 & 9,645 \\
\hline Source: ClinicalTrials.gov. Accessed July 8, 2009. & \\
\hline
\end{tabular}


gion could be a plus for all the countries to facilitate drug development.

\section{CHALLENGES AND OPPORTUNITIES FOR CHINA AND HONG KONG}

The rapidly evolving regulatory environment has inevitably led to some uncertainty for regulators and pharmaceutical manufacturers in understanding the relevant laws and regulations that govern the testing, registration, manufacture, import, marketing, and sale of pharmaceutical products. The demand for more transparency and communication-fostering mechanisms between the regulatory agency and the industry is increasing in China. Several regulatory agencies, such as US FDA, Japan's PMDA, and Taiwan's Department of Health have promoted public health by providing regulatory consultation to facilitate new drug development (12). The interaction between regulatory agencies and pharmaceutical manufacturers could be reinforced through regulatory consultation in China and Hong Kong.

In China, but not in Hong Kong, IND applications take 9 months review time as they require extensive CMC data and this is one of the major reasons for the long evaluation time in China. The drug lag in China is thought to be far behind the standard of Singapore (13), where a new drug already registered by benchmark agencies such as US FDA and European Medicines Agency (EMEA) can be registered for sale (ie, they have less regulated systems for pharmaceutical products). The long regulatory timeline for IND approval is one of the most significant barriers to drug development activities in China (not Hong Kong).

Hong Kong's market is relatively small, with its smaller population. Although Hong Kong is part of China, it has different health care and regulatory systems. There is no mutual recognition of registration between Hong Kong and China. Still, Hong Kong is officially accredited by China's SFDA and the clinical data for specific therapeutic areas generated in specific hospitals in Hong Kong can be used in support of registration in China as Chinese data. In addition to this advantage, Hong Kong has an ex- cellent internationalized infrastructure with a highly efficient regulatory framework. The ethics committee/IRB plays an important role in Hong Kong, with 2 to 3 months approval process for clinical testing of new drugs, mainly for safety concerns. Hong Kong has become one of the leading clinical trial cities in Asia.

Taiwan proposed the revival of the pharmaceutical evaluation report scheme at the 2008 Peru meeting for regulatory harmonization with a regional solution for global drug development (14). That is a model once very well accepted by EMEA to set up the standard of good review practice for members, to exchange assessment reports such as CMC and Common Technical Document, and to provide training on regulatory science.

Nevertheless, the incidents of contaminated heparin imported to the United States from China and melamine-contaminated milk products from China occurred in 2008. The US FDA launched the Beyond Our Borders Initiative (15). In November 2008, US FDA set up its first overseas offices in China (ie, Beijing, Shanghai, and Guangzhou), then in India, in the European Union (in Brussels, Belgium), in Latin America (Costa Rica), and in the Middle East. SFDA will work toward a system to certify that US FDA standards are met for products before they are exported to the United States. On February 27. 2009, SFDA's Center for Drug Evaluation issued "Working Procedure for Drug Registration Second Review." China has endeavored to upgrade its pharmaceutical regulatory framework for drug safety, the evaluation process, and the time needed for drug registration.

\section{CONCLUSION}

China has pledged to modernize its pharmaceutical regulatory systems to strive to become compatible with international standards. China's pharmaceutical regulatory system has evolved to encourage innovation, enhancing risk control to promote innovative drugs to be developed in China. The demand for more transparency and communication-fostering mechanisms between the regulatory agency and the industry is increasing in China. 
Drug trials in Hong Kong, within accredited therapeutic areas in recognized medical institutions, could be used in filing new drug applications in China as Chinese data. Hong Kong has an excellent internationalized infrastructure with a highly efficient regulatory framework. Hong Kong has become one of the leading clinical trial cities in Asia.

Regulatory cooperation among regional Asian countries may result in a win-win situation and a bright future for all. The developments and updates on the pharmaceutical regulatory systems in China and Hong Kong are of great interest to pharmaceutical manufacturers and researchers. Therefore, a snapshot of the evolution of pharmaceutical regulatory systems in China and Hong Kong may warrant great interest for further continuous observation and research.

Acknowledgments - The author wishes to express gratitude to Dr. Herng-Der Chern, executive director of the Center for Drug Evaluation, Taiwan, for his encouragement. The author also wishes to express gratitude to Ms. Fangmin Wang, director of the Drug Evaluation Department at the Center for Certification and Evaluation, Shanghai Food and Drug Administration. China, for reading the manuscript and providing valuable suggestions for revision.

This article was partly presented at the Regulatory Challenges in Pharmaceutical Market Asia Conference organized by the Asia Business Forum in Singapore, April 28-29, 2009.

\section{REFERENCES}

1. Central Intelligence Agency. The World Fact Book. https://www.cia.gov/library/publications/theworld-factbook/index.html. Accessed March 30. 2009.

2. China's foreign reserves top $\$ 2.13 t$ by June. http://www.chinadaily.com.cn/china/2009-07/ 15/content_8430837.htm. Accessed July 17, 2009.

3. Information Office of the State Council of the People's Republic of China. White paper: Status quo of drug supervision in China. July 2008, Bei- jing. http://eng.sfda.gov.cn/eng. Accessed July 4. 2009.

4. SFDA. Organizational chart and functions of SFDA, China (in Chinese). http://www.sfda.gov .cn/. Accessed July 4. 2009.

5. SFDA. The provisions for drug recall (SFDA Order No. 29). http://eng.sfda.gov.cn/eng. Accessed July 4, 2009.

6. SFDA. The requirements for on-site inspection for drug registration (in Chinese). http://www .sfda.gov.cn/. Accessed July 4, 2009.

7. SFDA. Special review and approval procedure for drug registration. SFDA Decree No. 21. http://eng.sfda.gov.cn/cmsweb/webportal/ W45649039/A64030241.html. Accessed July 4. 2009.

8. Pharmaceutical Service, Department of Health, Hong Kong. http://www.psdh.gov.hk/eps/index .jsp. Accessed March 30, 2009.

9. Ten reasons for conducting clinical trials in Hong Kong. http://www.hku.hk/ctc. Accessed March 30, 2009.

10. Tsuei SE. The role of the Asia-Pacific region in global drug development strategy. Drug $\ln f$ J. 2009:43:35-40.

11. US National Institutes of Health. Clinical trials registry. http://www.clinicaltrials.gov/. Accessed July 8, 2009.

12. Lin BB, Lin CH, Chern HD. The Critical Path Program in Taiwan. Drug Inf J. 2009:43:311 -317.

13. McAuslane N, Cone M. Collins J, Walker S. Emerging markets and emerging agencies: a comparative study of how key regulatory agencies in Asia, Latin America, the Middle East, and Africa are developing regulatory processes and review models for new medicinal products. Drug Inf J. 2009:43:349-359.

14. Lin CH, Lin BB, Chern HD. APEC pharmaceutical report (PER) scheme: a regional solution for global drug development. Drug Inf J. 2009:43: 305-309.

15. US FDA. Beyond Our Borders Initiative (Chapter 9. Operations in a Global Environment). http:// www.fda.gov/downloads/ICECI/Enforcement Actions/EnforcementStory/UCM129822.pdf. Accessed May 20, 2009.

The author reports no relevant relationships to disclose. 